\title{
RESERVOIR CHARACTERIZATION USING SEISMIC AND WELL LOGS DATA (A CASE STUDY OF NIGER DELTA) \\ "ESHIMOKHAI, S. and AKHIREVBULU, O.E.
}

\author{
http://dx.doi.org/10.4314/ejesm.v5i4.S20
}

\begin{abstract}
During analysis, hydrocarbon saturation in relatively unconsolidated sandstone reservoirs is a pore fluid property that has been successfully mapped using seismic surveys. The presence of hydrocarbon typically lowers the seismic velocity and density of unconsolidated to moderately consolidated sandstone and this in turn create different acoustic impedance (product of density and seismic velocity). This study reveals the petroleum potential and attempt to make available Petrophysical results for the various reservoirs in three (3) selected wells as these results will help enhance the proper characterization of the reservoir sands. The well log types used for quantitative analysis include resistivity, density and neutron logs. The gamma ray (GR) and calliper logs were mainly used for lithological identification, $V_{\text {sh }}$ was evaluated using linear and Steiber methods and Archie's equation was used in determining water saturation. The Petrophysical results reveal a good porosity $(0.26-0.34)$, water saturation $(0.09-0.32)$ and hydrocarbon saturation (0.77-0.83).
\end{abstract}

Received 19th June 2012; accepted 24th October 2012

Key words: Reservoir sand, Well log, Water saturation, Linear and Steiber.

\section{Introduction}

Reservoir Characterization generally determine the gross volume within the trap that has the potential to hold hydrocarbons, the accuracy of reservoir estimation such as thickness and others Petrophysical parameters of each reservoir is a critical element in interpretation, estimation of reservoir properties such as Porosity, Water Saturation and others parameter from seismic and well logs data. During analysis, seismic data can quantitatively predict reservoir parameters; one of such basic step is to compare the seismic volume at the location of a well to the well's information often through the intermediary of a synthetic seismogram (a model seismic track derived from sonic and density logs). During analysis, efforts focus on estimating subsurface physical properties of rock units which are important in hydrocarbon exploration and exploitation. The knowledge of reservoir characterization is an important factor in quantifying producible hydrocarbon (Schlumberger, 1989). Precisely reservoir characterization can be obtained from well logs especially using gamma ray and resistivity logs (Asquith, 2004). In other to map hydrocarbon reservoir, studies of geologic structure that can hold hydrocarbon in place must be considered, since hydrocarbon in geologic traps i.e. combination of rock structure that will keep oil and gas from migrating either vertically or laterally. Due to the need to thoroughly evaluate prospects so as to determine optimal production strategies and also minimize risk that may be associated with hydrocarbon exploration has driven the development of an array of techniques which attempt to propagate log properties. One of such techniques in use is the deterministic and linear physical relationship between log properties and the corresponding seismic response of subsurface rock units (Muslim and Moses, 2011).

Well logs interpretation can be used in obtaining vital information and required properties, since a complete coring and core analysis of the entire pay zone is impractical.

A typical seismic section of Niger Delta will reveal number of synsedimentary structures resulting from the deltaic tectonic. The structures include growth faults; which are normal faults characterization by a concave fault plane resulting from the decrease of dip at depth. The growth index will be equal to unit thickness in down thrown block divided by unit thickness in the up thrown block and it value varies from $1-2.5$. Rollover anticlines are associated to growth 
faults and result from dragging of the down dip block against the fault plane. Antithetic fault are synsedimentary structures but with a counter dip. Back to back structures are limited by the growth fault and antithetic fault. Clay ridges are located on the continental slope and their deepening increase rapidly inside the delta where only their crest is visible on the seismic section (Balarabe, 2003).

The aim of this paper is to use an integrated technique in computing various Petrophysical parameters, these techniques include using well $\log$ data and combining various mathematical equations $(1-5)$ which ranges from the linear, non-linear $\left(\mathrm{V}_{\mathrm{sh}}\right.$ Stieber $)$ and the Archie's equations. From the data use in computing the Petrophysical results such as the log data which consist of gamma ray, resistivity, density and neutron logs, the Stieber and Archie's equations were applied in carrying out Petrophysical evaluation such as the water saturation, porosity and the hydrocarbon saturation and the results obtained were summarized in (Table 1,2 and 3 ), this results will be compared with the recommendation results of random core samples from selected wells so as to establish and reduce interpretational errors.

\section{Methodology \\ Study Area}

The Niger Delta Basin is situated at the southern end of Nigeria boarding the Atlantic Ocean and extends from about Longitude $30^{\circ}$ $00^{\prime} \mathrm{E}$ to $9^{0} 00^{\prime} \mathrm{E}$ and Latitude $4^{0} 3^{\prime} \mathrm{N}$ to $5^{0} 20^{\prime} \mathrm{N}$ (Lambert, 1981).

\section{Geology}

It is the youngest sedimentary basin within the Benue trough system. The Niger development began after the Eocene tectonic phase, having the Niger and Benue Rivers as is main supplier of sediments. Three lithostratigraphic units are distinguishable in the Tertiary Niger Delta. The Akata formation which is predominantly marine prodelta shale is overlain by the paralic sand/shale sequence of the Agbada Formation. The upper most section is the continental upper deltalic plain sands - the Benin formation. Virtually all the hydrocarbon accumulations in the Niger Delta occur in the sands and sandstones of Agbada formation where they are trapped by rollover anticlines related to growth fault development (Ekweozor and Dankoru, 1994).

\section{Reservoir Rocks}

We can define reservoir rock as one that has porosity and permeability that allows it to contain a significant amount of extractable hydrocarbon. Petroleum reservoir in the Niger Delta is produced from sandstone and unconsolidated sands predominantly in the Agbada formation. The characteristic of the reservoirs in the Agbada formation are controlled by depositional environment and the depth of burial (known) reservoir rocks are Eocene to Pliocene (Evamy et al., 1978). Hydrocarbon are found in reservoir rock, that is, any combination of rock structure that will keep oil and gas from migrating either vertical or laterally (Wan Qin, 1995), majority of the traps in Niger Delta are structural and to locate, horizons are picked and faults mapped on seismic inclines and crosslines to produce the time structure map. For there to be petroleum accumulation a set of geological circumstance is needed for the accumulation of Oil and Gas to recapitulate, these are;

(1) A migrations route for the hydrocarbon to move from the source to the traps.

(2) The existence of a suitable trap structure.

(3) Burial of the source rock to maturity.

(4) The trinity of source, reservoir and seal rocks.

\section{Sampling/Data Collection}

The data used in this study consist of digital seismic data, a suit of well logs; the well $\operatorname{logs}$ suite consists of Gamma ray, Resistivity, Neutron and Density logs which will be used in evaluating Petrophysical properties such as Hydrocarbon saturation $\left(\mathrm{H}_{\mathrm{c}}\right.$ _sat), Porosity $(\Phi)$, Water Saturation $\left(S_{\mathrm{w}}\right)$ and Water Resistivity $\left(\mathrm{R}_{\mathrm{w}}\right)$. The Gamma ray and Resistivity logs are use in determining the reservoir zones and the presence of hydrocarbon. The details method applied are as follows;

$\mathrm{V}_{\mathrm{sh}}$ from natural Gamma ray using Linear and Steiber Methods

(1) $\mathrm{V}_{\mathrm{sh}}$ linear $\left(\mathrm{V}_{\mathrm{sh}}-\mathrm{gr} \_\mathrm{l}\right)=\frac{\mathbf{G R}-\mathbf{G R}_{\mathrm{CL}}}{\mathbf{G R}_{\mathbf{S H}}-\mathbf{G R}_{\mathrm{CL}}}$

(2) The above equation expresses $V_{\text {sh }}$ linear with increase of gamma ray reading 
Where;

$\mathrm{GR}=$ Gamma ray $\log$ reading in zone of interest (API units)

$\mathrm{GR}_{\mathrm{CL}}=$ Gamma ray $\log$ reading in $100 \%$ clean zone

$\mathrm{GR}_{\mathrm{SH}}=$ Gamma ray log reading in $100 \%$ shale

(3) $V_{\text {sh }}$ Steiber $\left(V_{\text {sh _gr_s }}\right)=\frac{\mathbf{0 . 5} \times V_{\text {sh_gr_l }}}{\mathbf{1 . 5}-V_{\text {sh_gr_l }}} 2$

From the above methods, the non-linear gamma ray $\left(\mathrm{V}_{\mathrm{sh}}\right.$ Steiber) will predict less $\mathrm{V}_{\mathrm{sh}}$ than the linear method. The non-linear method is usually used in unconsolidated rocks since they are known to be more chemically immature and may contain radioactive minerals such as Feldspars which can contribute to gamma but unrelated to shale volume.

(4) The formation Resistivity Factor (FRF); also called the formation factor $(\mathrm{F})$ was computed using

$\mathbf{F}=\frac{\mathrm{a}}{\boldsymbol{\Phi}^{\mathrm{m}}}$

Where;

$\mathrm{A}=$ constant related to texture, its value is assumed to be 0.62 for sandstone

$\Phi=$ represent the total porosity of the formation

$\mathrm{m}=$ cementation factor

Perhaps the use of values of $m=2, a=1$ and $n$ $=1$.

(5) The water Saturation level is calculated using the Archie's equation as stated below

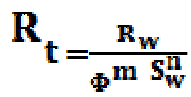

That is,

$S_{W}^{n}=\frac{R_{w}}{R_{t \Phi}}$
This implies that;

$S_{w}=\sqrt[n]{\frac{R_{w}}{R_{t \Phi^{n}}}}$

Where;

$\mathrm{R}_{\mathrm{t}}=$ the true formation resistivity or total resistivity of the hydrocarbon formation

$\left(\mathrm{H}_{\mathrm{c}}\right)$

$\mathrm{S}_{\mathrm{w}}=$ the water saturation level

$\mathrm{n}=$ the saturation exponent, which describes the geometry of the current flow path through the water body in the presence of hydrocarbon

$\Phi=$ the total porosity

$\mathrm{m}=$ the cementation exponent

$\mathrm{R}_{\mathrm{w}}=$ the water resistivity

(6) The porosity values was computed using the below equation

$\Phi=\frac{\boldsymbol{P}_{\mathrm{ma}}-\boldsymbol{P}_{\mathrm{b}}}{\boldsymbol{\rho}_{\mathrm{ma}}-\boldsymbol{P}_{\mathrm{f}}}$

Porosity can also be evaluated from modified Archie's equation in the presence of shale (Schlumberger, 1989).

$$
\frac{1}{\mathbf{R}_{\mathrm{t}}}=\frac{\phi^{\mathrm{m}} \mathbf{S}_{\mathrm{w}}^{2}}{\mathbf{a R}_{\mathrm{w}}\left(\mathbf{1}-\mathrm{V}_{\mathrm{sh}}\right)}+\frac{V_{\mathrm{sh}} \mathbf{S}_{\mathrm{w}}}{\mathbf{R}_{\mathrm{sh}}}
$$

Where;

$$
\Phi=\text { porosity }
$$

$\rho_{\mathrm{ma}}=$ the matrix density

$\rho_{\mathrm{b}}=$ the bulk density

$\rho_{\mathrm{f}}=$ the fluid density

$\mathrm{R}_{\mathrm{t}}=$ formation resistivity

$\mathrm{m}=$ cementation factor

$\mathrm{S}_{\mathrm{w}}=$ Water saturation

$\mathrm{a}=$ formation factor coefficient

$\mathrm{R}_{\mathrm{w}}=$ formation fluid resistivity

$\mathrm{V}_{\mathrm{sh}}=$ volume of shale

$\mathrm{R}_{\mathrm{sh}}=$ resistivity of the shale 


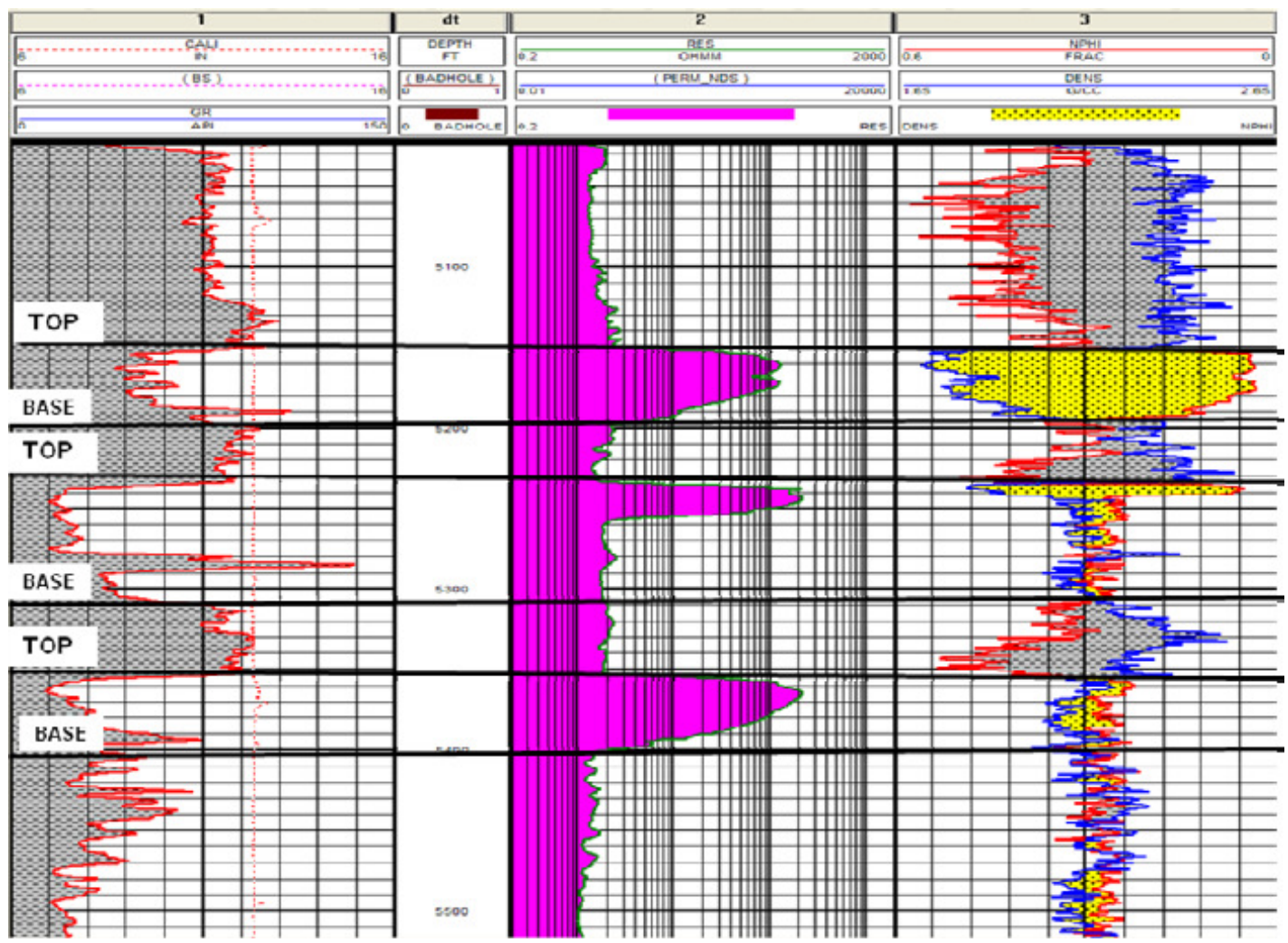

Figure 1 Composite Log for Well 1

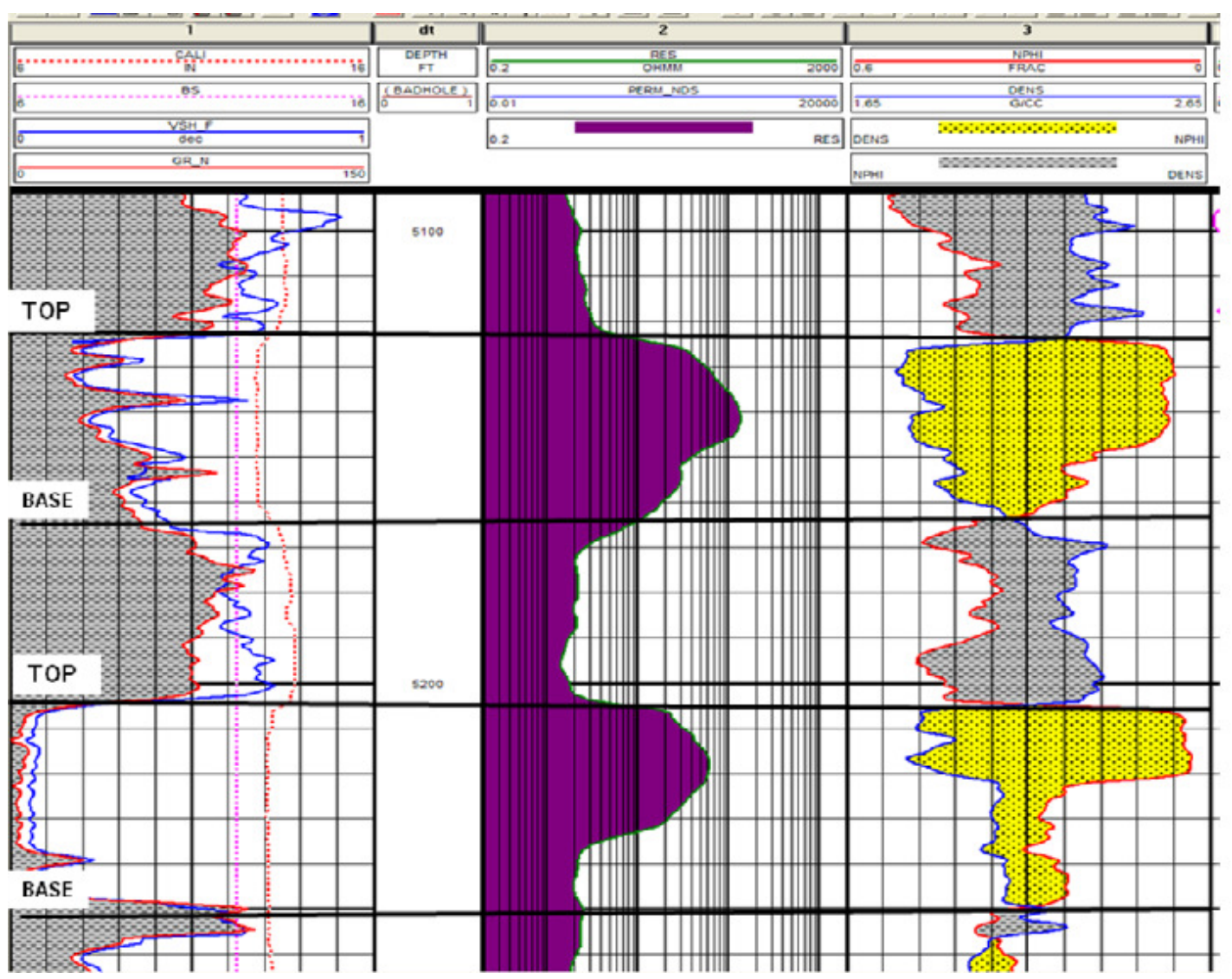

Figure 2 Composite Log for Well 2 
Ethiopian Journal of Environmental Studies and Management EJESM Vol. 5 no.4 (Suppl.2) 2012

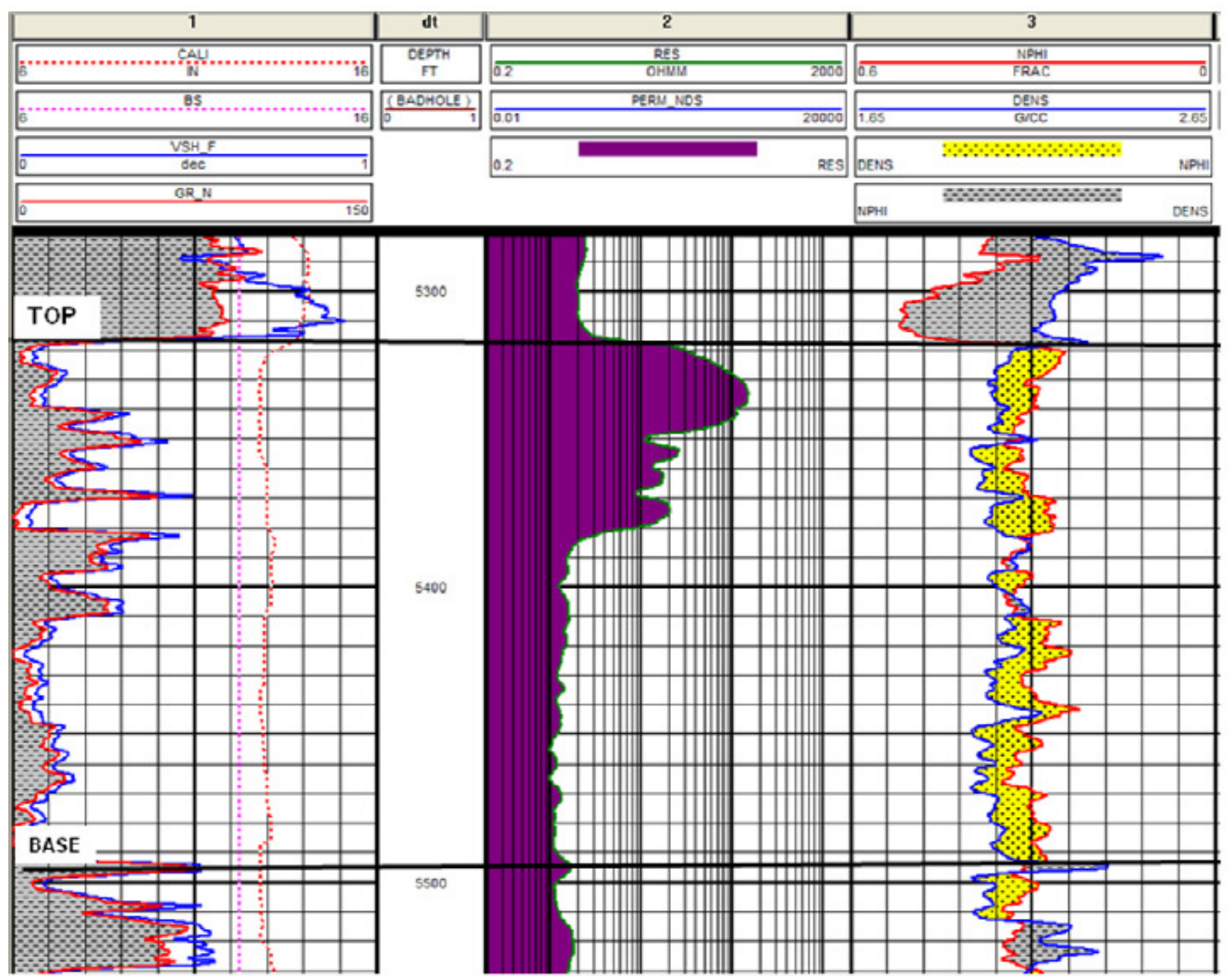

Figure 3 Composite Log for Well 3

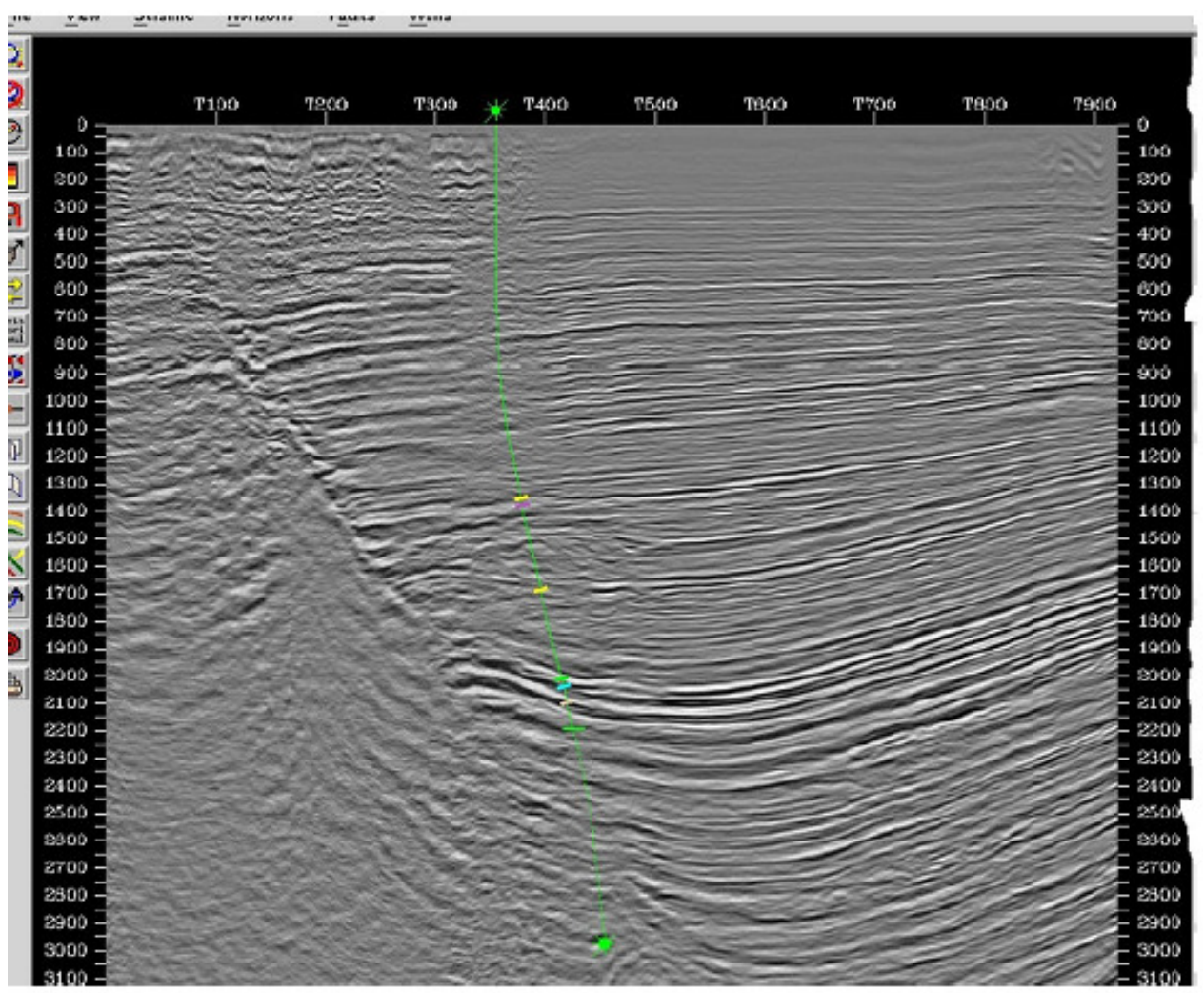

Figure 4 Siesmic Section Showing a Drilled Well 
Table 1 Computed Petrophysical Parameters from Well 1

\begin{tabular}{|c|c|c|c|c|c|c|c|c|c|c|c|}
\hline $\begin{array}{l}\text { Well } \\
1\end{array}$ & 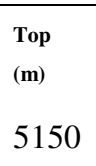 & 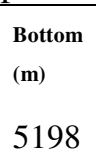 & $\begin{array}{l}\text { Thickness } \\
\text { (m) }\end{array}$ & GR & Density & Rt_den & Fluid_den & Phi & $\overline{\mathbf{R}_{w}}$ & $\mathbf{S}_{\mathbf{w}}$ & $\mathbf{H}_{\mathbf{c} \_ \text {sat }}$ \\
\hline A & 5150 & 5160 & 10 & 63 & 1.80 & 200 & 0.2 & 0.347 & 0.324 & 0.104 & 0.896 \\
\hline B & 5160 & 5168 & 8 & 58 & 1.85 & 200 & 0.2 & 0.323 & 0.324 & 0.110 & 0.890 \\
\hline $\mathrm{C}$ & 5168 & 5170 & 2 & 60 & 1.87 & 200 & 0.2 & 0.318 & 0.324 & 0.113 & 0.889 \\
\hline D & 5170 & 5194 & 24 & 62 & 1.81 & 30 & 0.2 & 0.345 & 0.324 & 0.272 & 0.728 \\
\hline $\mathrm{E}$ & 5194 & 5198 & 4 & 86 & 1.90 & 8 & 0.2 & 0.306 & 0.324 & 0.324 & 0.416 \\
\hline
\end{tabular}

Average Phi $=$ sum of $\frac{(\mathrm{Phi} * \text { Thickness })}{\text { Thickness }}=\frac{16.171}{48}=\mathbf{0 . 3 3 7}$

Average $S_{w}=\frac{3.677}{16.171}=\mathbf{0 . 2 2 7}$

Average $\mathrm{H}_{\mathrm{c}-}$ sat $=\underline{12.495}=\underline{\mathbf{0 . 7 7 3}}$

$$
16.171
$$

Table 2 Computed Petrophysical Parameters from Well 2

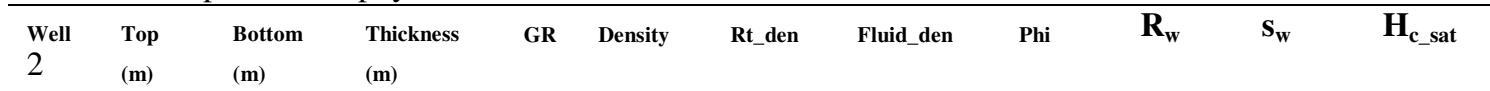

$5233 \quad 5260$

\begin{tabular}{llllllllllll}
\hline A & 5233 & 5238 & 5 & 33 & 1.85 & 300 & 0.2 & 0.327 & 0.324 & 0.090 & 0.910 \\
B & 5238 & 5245 & 7 & & 1.90 & 297 & 0.2 & 0.306 & 0.324 & 0.096 & 0.904 \\
C & 5245 & 5260 & 15 & & 2.07 & 50 & 0.7 & 0.290 & 0.324 & & \\
\end{tabular}

Average $\mathrm{Phi}=\underline{8.126}=\mathbf{0 . 3 0 1}$

Average $S_{\mathrm{w}}=\underline{1.142}=\underline{\mathbf{0 . 1 7 5}}$

8.126

Average $\mathrm{H}_{\mathrm{c}}$ - $\mathrm{sat}=\underline{6.707}=\mathbf{0 . 8 2 5}$

8.126

Table 3 Computed Petrophysical Parameters from Well 3

\begin{tabular}{llllllllllll}
\hline Well 3 & $\begin{array}{l}\text { Top } \\
(\mathbf{m})\end{array}$ & $\begin{array}{l}\text { Bottom } \\
(\mathbf{m})\end{array}$ & $\begin{array}{l}\text { Thickness } \\
(\mathbf{m})\end{array}$ & GR & Density & Rt_den & Fluid_den & Phi & $\mathbf{R}_{\mathbf{w}}$ & $\mathbf{S}_{\mathbf{w}}$ & $\mathbf{H}_{\mathbf{c} \_ \text {sat }}$ \\
\hline & 5355 & 5400 & & & & & & & & & \\
A & 5253 & 5362 & 9 & 30 & 2.1 & 50 & 0.65 & 0.26 & 0.32 & 0.28 & 0.743 \\
B & 5362 & 5400 & 38 & 35 & 2.05 & 60 & 0.65 & 0.30 & 0.32 & 0.22 & 0.783 \\
Water & 5475 & 5510 & 35 & 30 & 2.05 & 2 & 1 & 0.36 & 0.36 & - & -
\end{tabular}




$$
\begin{aligned}
& \text { Average } \mathrm{Phi}=0.295 \\
& \text { Average } \mathrm{S}_{\mathrm{w}}=0.224 \\
& \text { Average } \mathrm{H}_{\mathrm{c}} \text { sat }=0.776
\end{aligned}
$$

\section{Results and Discussion}

Evaluation and identifying reservoir zone is based on the ability of the interpreter to make use of available data in interpreting various parameters, attribute maps extracted on top of key horizons were used for better visualization and interpreting the morphological and reflectivity characteristics of the reservoir. The results of the interpreted well $\operatorname{logs}$ revealed that the hydrocarbon interval in the areas occur between the depth range of $5150-5198 \mathrm{~m}$ for Well 1, 5233 $5260 \mathrm{~m}$ for Well 2 and $5353-5400 \mathrm{~m}$ for Well 3.

The gamma ray and the resistivity logs shows that the reservoir are good quality reservoir sands with porosities averaging between $0.26-0.34$, water saturation averaging between $0.09-0.32$ and the hydrocarbon saturation averaging between $0.77-0.83$ with thickness of the reservoirs sands ranging from $27-48 \mathrm{~m}$.well to seismic tie also reveal that the sands are hydrocarbon bearing reservoirs and has hydrocarbon indicators on seismic section. From the well $\operatorname{logs}$ used, (figure $1-3$ ) and the results obtained (Table $1-3$ ) reflects the reservoir zones and the Petrophysical parameters obtained from the well logs, from the well logs data it was noted that the reservoirs are separated by shales as these shales servers as seal to the reservoir.

\section{Conclusion}

For good Petrophysical analysis and reservoir evaluation of the subsurface reservoir, core samples should be taken randomly from well as this will help to establish Petrophysical parameters like permeability and other fluid densities in the various zone which will also be of better advantage in porosities evaluation. Quantitative porosity and water saturation values obtain from Petrophysical well $\log$ analysis are good enough for hydrocarbon production.

\section{References}

Asquith, N. (2004), Basic Well Log Analysis for Geologists. A.A.P.G. Methods in Exploration. Tulsa, Oklahoma, No. 16. Pp. 12 $-135$.

Balarabe, H.J. (2003), Interpretation of Madu field 3D Seismic Data and Prospect Generation, A Paper Delivered at a Technical Section to Exploration/Asset Department Texaco Overseas Petroleum Company of Nigeria.

Ekweozor, C.M. and Dankoru, E.M.(1994), North Delta depobelt portion of the Akata Agbada (1) Petroleum System, Niger Delta, Nigeria, in Magon, L.B., and Dow, W.G., eds. The petroleum system from source to trap. A.A.P.G memoir 60; Tulsa, 599 -614

Evamy, B.D., Haremboure, J., Kamerling, P., Molloy, F.A., and Rowland, P.H. (1978), Hydrocarbon habitat of tertiary Niger Delta; A.A.P.G Bulletin 2008. Pp. 30 - 32

Lambert, A. (1981), The Niger Delta Complex Basin, Journal of Petroleum Geology, 1(2), 78 $-98$

Muslime, B.M., and Moses. A.O. (2011),

Reservoir Characterization and PaleoStratigraphic imaging over Okari Field, Niger Delta using neutral networks; The Leading Edge, 1(6), 650 -655.

Schlumberger, (1989), Log Interpretation, Principle and Application: Schlumberger Wireline and Testing, Houston Texas, pp. 21 89.

Wan Qin, (1995), Reservoir Delineation using 3-D Seismic Data of the Ping Hu Field, East China, Unpublished MSc thesis, University of Colorado Boulder pp 6 - 8 